\title{
Updating of digital topographic maps in the new national spatial coordinate system: case Fergana valley in Uzbekistan
}

\author{
Fazilova Dilbarkhon ${ }^{\mathrm{a}, \mathrm{b} *}$, Magdiev Hasan ${ }^{\mathrm{a}, \mathrm{c}}$ \\ a Ulugh Beg Astronomical Institute of Uzbek Academy of Science, 100052, Astronomicheskaya 33, Tashkent, Uzbekistan, E-mail: \\ dil_faz@yahoo.com \\ ${ }^{b}$ Tashkent State Technical University named after Islam Karimov, 100095, University str, 2 Tashkent, Uzbekistan \\ ${ }^{c}$ Agency for cadaster of the Republic of Uzbekistan, 100097, Choponota, 5 Tashkent, Uzbekistan, E-mail: hasan.magdiev@gmail.com \\ * Corresponding author
}

\begin{abstract}
The classical geodetic coordinate system (CS42) in Uzbekistan uses the Krasovsky ellipsoid. The implementation of new information technologies, such as the Global Navigation Satellite System, became the basis for the development of a new national open geocentric coordinate system. This paper describes the development of a distortion grid for transforming horizontal spatial data from the local geodetic datum CS42 to a geocentric datum WGS84 for 1:100000 scale maps of the Fergana Valley in Uzbekistan. A first version of the distortion grid file has been created for transforming between CS42 and WGS84 for the whole territory of the country. The significant influence of the longitudinal drift of the region has been confirmed. The grid was used to transform topographic maps at a scale of 1:100 000 for the Fergana Valley. Changing the map datum has shifted the grid of coordinate systems by $70 \mathrm{~m}$ in the East and $7 \mathrm{~m}$ in the North.
\end{abstract}

Keywords: CS42, WGS84, distortion grid, topographic maps

\section{Introduction}

The implementation of new information and telecommunication technologies has made it possible to solve in a new way the problems of coordinate-time support. The widespread use of satellite methods, such as the Global Navigation Satellite System (GNSS), became the basis for the development of the National geographic information system (NGIS) in Uzbekistan and the task of developing the foundations for the creation and use of a new national open coordinate system (Resolution, 2017). In 2005, the program on creating GNSS measurementsbased State Geodetic Network (SGN) has started in the country. Significant results achieved on the creation of the Fundamental Astro-Geodetic Network (FAGN), improvement of methods of its construction, and increase in accuracy of coordinates by the introduction of new technologies of measurements and collocation with the existing stations of the International GNSS network (Kitab, Tashkent, Maydanak and Maidantal).

World Geodetic System (WGS-84) is a reference frame for the GNSS system. However, until now, Uzbekistan uses the local reference geodetic system Coordinate System 1942 (CS42), based on Krasovsky ellipsoid for the coordinate-time support. The national height system of the country is the Baltic normal height system. It was adopted in 1977 and referenced to the mean sea level with zero-mark of the Kronstadt tide gauge in Pulkovo. Factors such as the method of implementation of CS42, its orientation in space, and, especially, regional geodynamic features have led to a difference in determining the position of objects in these geodetic systems from several meters to several hundred meters (Makarenko and Demyanov, 2002).

To date, the geodetic enterprises in the country have a large amount of cartographic material, the coordinates of which are determined in the Gauss-Kruger system of 1942, and the heights - in the Baltic normal height system. To make the most of the geodetic and cartographic potential that was created so far, the task arose of providing users with methodology and data to facilitate the transformation of coordinates between the local CS42 and WGS84 ellipsoid based geocentric coordinate system. In this paper, the procedure for constructing a displacements grid from the CS42 coordinate system to a new geocentric system based on the WGS84 ellipsoid using data from the new GNSS network of Uzbekistan is considered. Further, the grid was used to update topographic maps at a scale of 1: 100 000 of the Fergana Valley. 


\section{Data handling}

\subsection{CS42 data}

The CS42 coordinate system was established in 1942 after joint adjustment separate blocks of triangulation and 2-3 classes polygonometry by string method. The coordinates of Pulkovo had been specified as the starting point. The network incorporated approximately 14000 points of first- four classes. About 325 points of the firstorder network and 992 points of the fourth-order network were restored during the installation of the GNSS network. To date, 164 stations of the GNSS network are "common points" with known coordinates in both datum. The CS42 system is represented mainly by control points with coordinates were initially given in the rectangular plane of Gauss-Krüger projection $(x, y)$ and normalorthometric height $(H)$, where ellipsoidal height $(h)$ in CS42 datum is not known. Equations are given in GOST (2017) were used for the conversion from rectangular plane coordinates in Gauss-Kruger projection to the ellipsoidal $(B, L)_{\mathrm{CS} 42}$ coordinates in CS42 datum.

\subsection{GPS data}

The SGN was established in the country based on the availability of infrastructure and geographical needs and therefore, it does not cover the entire country (Figure 1). It includes about 164 stations of several subnetworks. Continuous Reference Station System (CRS) and Satellite geodetic network 0 -th class points (SGN-0) networks were first installed from 2005 to 2006 , followed by the installation of a Satellite geodetic network first class points (SGN-1) network in 2010-2014.

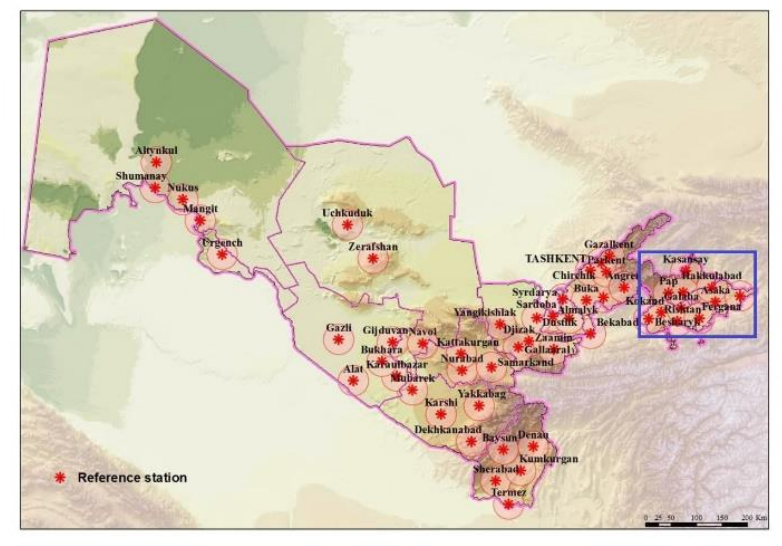

Figure 1. Satellite Geodetic Network stations distribution (test area is highlighted in a blue square).

Measurements of the network were performed using only the Global Positioning System (GPS) and further, we will consider only this data processing. Raw GPS observations RINEX (Receiver INdependent EXchange) files were checked and edited with TEQC software (Estey and Meertens, 1999). GPS measurements were processed with GAMIT/GLOBK ver. 10.71 software (Herring et al., 2015) for relative positioning in three steps (Dong et al., 1998). Processing was carried out according to the IERS2010 recommendations (Petit and Luzum, 2010). The elevation cut-off angle was set to $15^{\circ}$. At first, to identify discontinuities, data gaps daily station positions, atmospheric zenith delays of each point, and Earth orientation parameters (EOPs) were estimated using double differenced GPS phase measurements and IGS final products. Global Pressure and Temperature GPT2 mapping function (Lagler et al., 2013) and the ocean tideloading model (Lyard et al., 2006) were applied. Ambiguities were resolved with $90 \%$ for the wide lane and $80 \%$ for the narrow lane. To tie the regional measurements to an external global reference frame, data coming from 11 continuously operating global tracking stations (artu, badg, chum, guao, hyde, iisc, irkt, kit3, mdvj, pol2, tash), mostly from the IGS permanent network, were introduced in the processing. The reliability of the IGS stations was characterized by the days, which have at least $95 \%$ data coverage and have a uniform distribution around the studied regional network. In the following step, the GAMIT solutions were combined using a Kalman filter estimator in GLOBK software package (Herring et al. 2015) to estimate a consistent set of positions in the International Terrestrial Reference Frame ITRF2014 (Altamimi et al., 2016).

\subsection{Generation of the shift grid}

As a rule, local and geocentric datums must have homogenous accuracies. However, the coordinates are not the same accuracies due to the orientation of the reference-ellipsoids and local deformations of classical astrogeodetic networks. Besides, conformal coordinate transformations, in this case, are not accurate enough due to the heterogeneity of spatial data in different geodetic datum (Featherstone and Vanicek, 1999). On the other hand, there are no precise definitions of the local geoid for this area and studies on the use of global geopotential models of the Earth, open-source DEM are being carried out (Fazilova and Magdiev, 2018; Fazilova et al., 2021). According to recent studies, conformal coordinate transformations are very often improved by the implementation of distortion grids (grid-based 
transformation models). Grid-based transformations are already in use in many countries such as the USA (Dewhurst 1990), Canada (Junkins and Farley 1995), Australia (Collier 2002), and so on. Known as the National Transformation Version 2 (NTv2) grid (Junkins and Farley, 1995) provided much-improved distortion modelling that adapted to the variations in the spatial density of network points in Canada, Australia. The grid must be obtained from known reference "common points" in both systems.

In modelling the shift grid, the difference between the latitude, longitude, and height of the two datum is first defined. In a datum conversion, we essentially intend to determine differences in longitude $(d L)$, latitude $(d B)$ and geoid undulations $(\zeta=h-H)$. Once the shift for each common point is defined in three dimensions, distortion grid files for horizontal $(d B, d L)$ and vertical $(d H)$ components of coordinates were constructed by applying the Minimum Curvature interpolation method of the Golden Surfer mapping package. The distortion grid has been computed at a spacing $4^{\prime}$ in longitude and $3^{\prime}$ in latitude, taking into account the minimum distance between the reference stations. Further, the matrices of horizontal in NTv2 format and vertical distortions in NOAA GTX format were created using the open-source library GDAL.

\subsection{Test area}

The territory of the Fergana Valley in Uzbekistan was selected for updating topographic maps of a scale of 1 : 100000 (see the area is highlighted in a blue square in Figure 1). The basin is the largest intermountain depression in Central Asia, between the mountain systems of the Tien-Shan in the north and the Gissar-Alai in the south. The valley is approximately 300 kilometers long and up to 70 kilometers wide, forming an area covering 22,000 square kilometers. The choice of this area is due to several reasons. First, the early work on the topographic support of the Central Asian region began at the beginning of the 20th century and most of the measurements to create a unified triangulation system were carried out here. On the other hand, GPS stations of the SGN are installed mainly in areas with developed infrastructure and this territory has a uniformly distributed network of tracking stations. Also, the varied topography of the area from flat to mountainous part is a good model for testing displacement grid and estimation the transformation procedure.

\section{Results and discussion}

At the first stage of the analysis, we considered the statistical analysis of the obtained deformation matrices. To estimate the error, the mean value, standard deviation, and maximum values for the horizontal $(d B, d L)$ coordinate differences were calculated (Table 1). One of the reasons for the maximum error value of horizontal displacements in the longitude component may be the influence both of the tectonic motion in the region and the error of classical methods (Reigber et.al, 2001; Fazilova et al., 2018).

\begin{tabular}{|l|c|c|}
\hline & $d B$ & $d L$ \\
\hline Min, m & 0,098 & $-150,841$ \\
\hline Max, m & 20,838 & 283,656 \\
\hline Mean, m & 14,545 & 89,287 \\
\hline st.dev, m & 5,619 & 144,287 \\
\hline
\end{tabular}

Table 1. The statistics of the transformation from CS42 to WGS84 (values in meters).

To evaluate how accurately the conversion itself is performed, the SGN stations coordinates in Fergana valley were transformed from CS42 to WGS84. Namely, we compared the «calculated» and «measured» coordinates of GPS points. The discrepancy in coordinates varies from $-0.77 \mathrm{~m}$ to $0.62 \mathrm{~m}$ with an average value of $0.004 \mathrm{~m}$ in the North component and from $-23.56 \mathrm{~m}$ to $31.35 \mathrm{~m}$ with an average value of -0.17 $\mathrm{m}$ for the East component (Figure 2).

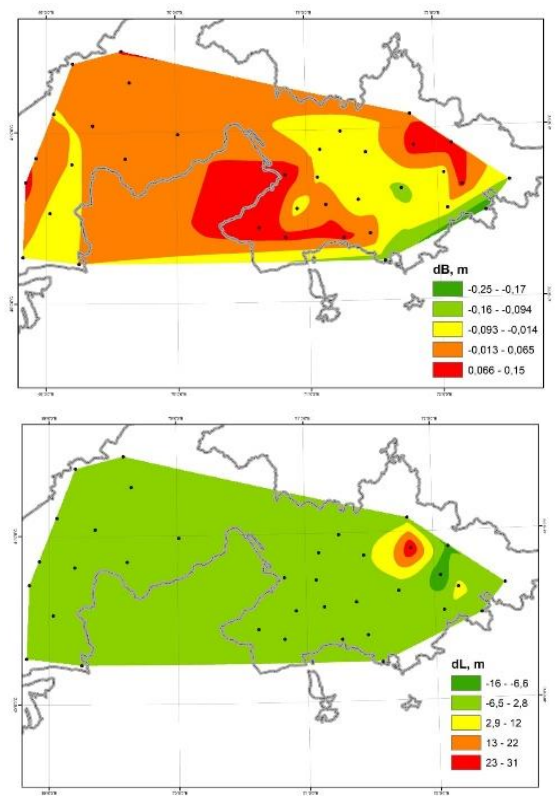

Figure 2. Comparison of the «calculated» and «measured» coordinates of GPS points 
We selected a grid of 49 points on the topographic map of the study area. The size of one cell is $1585 \mathrm{\kappa m}^{2}$ (Figure 3, top). Rectangular plane coordinates in Gauss-Kruger projection $(x, y)_{\mathrm{CS} 42}$ were transformed into the ellipsoidal $(B, L)_{\mathrm{CS} 42}$ coordinates. The obtained coordinates using the constructed grid are transformed into the geocentric system WGS84 $(B, L)_{\mathrm{WGS} 84}$, and, respectively, into the rectangular plane coordinates $(x, y)_{W G S 84}$ in UTM coordinate system. When transforming into WGS84, one should proceed from the fact that the nomenclature and layout of topographic maps remain the same, that is, the coordinates of the corners of the nomenclature sheet and other points of the mathematical basis do not change to a degree. In this case, due to changes in the parameters a and $\alpha$ of the geocentric reference ellipsoid WGS84 concerning the parameters of the Krasovsky reference ellipsoid, the plane coordinates of the points will receive displacements. In our case, for the considered grid of the Fergana valley, we had an offset in longitude equal to 70 $\mathrm{m}$ and for latitude equal to $7 \mathrm{~m}$ (Figure 2, bottom).
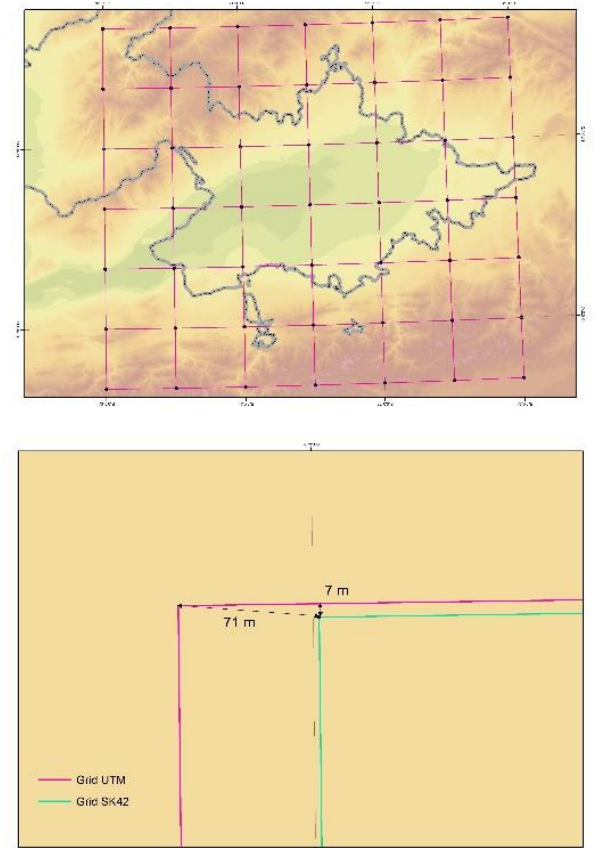

Figure 3. Grid of topographic map before and after transformation (top). The coordinate difference of the corners of the grid on an enlarged scale (bottom).

\section{Conclusions}

In this work, we studied the transformation of the classic horizontal datum CS42 into a new geocentric coordinate datum, based on the WGS84 ellipsoid. For this, at the first stage, a first version of the distortion grid was created using classical and satellite measurements at common points of the geodetic network of the Republic of Uzbekistan. It was found, that the grid has significant deformations in the longitudinal component. This confirms the influence of tectonic phenomena in this region. Further, the grid was used to transform topographic maps at a scale of 1:100 000 for the Fergana Valley. The obtained displacement for the East component is $70 \mathrm{~m}$, and for the North component, the displacement is $7 \mathrm{~m}$.

\section{References}

Altamimi, Z., Rebischung, P., Métivier, L., and Collilieux, X. (2016). ITRF2014: A new release of the International Terrestrial Reference Frame modeling nonlinear station motions, Journal of Geophysical Research: Solid Earth, 121(8), 6109-6131. https://doi.org/10.1002/2016jb013098

Collier, P., 2002. Development of Australia's National GDA94 Transformation Grids. Consultant's Report to the Intergovernmental Committee on Surveying and Mapping, University of Melbourne, Australia.

Dewhurst, W.T. (1990). NADCON: The application of minimum curvature-derived surfaces in the transformation of positional data from the North American Datum of 1927 to the North American Datum of 1983. NOAA Technical Memorandum NOS NGS-50. Silver Spring, Maryland: National Geodetic Survey, NOAA.

Dong, D., Herring, T. A., and King, R. W. (1998). Estimating regional deformation from a combination of space and terrestrial geodetic data. Journal of Geodesy, 72(4), 200-214. https://doi.org/10.1007/s001900050161

Estey, L. H. and Meertens, C. M. (1999). TEQC: The Multi-Purpose Toolkit for GPS/GLONASS Data, GPS Solutions (pub. by John Wiley \& Sons), 3(1), 42-49. https://doi.org/10.1007/PL00012778

Fazilova, D., Ehgamberdiev, S., \& Kuzin, S. (2018). Application of time series modeling to a national reference frame realization. Geodesy and Geodynamics, 9(4), 281-287. https://doi.org/10.1016/j.geog.2018.04.003

Fazilova, D. \& Magdiev, H. (2018). Comparative study of interpolation methods in development of local geoid. International Journal of Geoinformatics, 14(1), pp. 2933.

Fazilova, D., Magdiev, K. and Sichugova, L. (2021). Vertical Accuracy Assessment of Open Access Digital 
Elevation Models Using GPS. International Journal of Geoinformatics, 17(1), pp. 19-26.

Featherstone, W. E. and Vanicek, P., 1999. The Role of Coordinates and Heights in Horizontal Datum Transformations. The Australian Surveyor, Vol. 44, No. 2: 143-150.

GOST_r_32453-2017. (2017). Global Navigation Satellite System. Coordinate systems. Methods for transforming coordinates of defined points. Moscow, Russia.

Herring, T.A., King, R.W., Floyd, M., McClusky, S.C. (2015). Introduction to GAMIT/GLOBK. Release 10.6. Technical report. Massachussetts Institute of Tectonology.

Junkins, DR and Farley, SA. (1995). National transformation version 2 NTv2 - user's guide. Geodetic Survey Division, Geomatics Canada.

Lagler, K., Schindelegger, M., Böhm, J., Krásná, H., and Nilsson,T. (2013). GPT2: Empirical slant delay model for radio space geodetictechniques, Geophys. Res. Lett., 40, pp. 1069-1073.

Lyard, F., Lefevre, F., Letellier, T. et al. (2006). Modelling the global ocean tides: modern insights from FES2004. Ocean Dynamics 56, 394-415 https://doi.org/10.1007/s10236-006-0086-X

Makarenko, N. L. \& Demyanov G. V. (2002). Coordinate system SK-95 and ways of further development of the state geodetic network. Information bulletin of the GISAssociation, 1 (33) - 2 (34), pp. 5-8. In Russian

Petit, G., Luzum, B. IERS Conventions. (2010). Verlag des Bundesamts für Kartographie und Geodäsie, 2010

Reigber, C., Michel, G. W., Galas, R., Angermann, D., Klotz, J., Chen, J. Y.,... Ishanov, M. C. (2001). New space geodetic constraints on the distribution of deformation in Central Asia. Earth and Planetary Science Letters, 191(1-2), 157-165. https://doi.org/10.1016/s0012-821x (01)00414-9

Resolution Cabinet of Ministers of the Republic of Uzbekistan. On the application and open use of international geodetic coordinate systems on the territory of the Republic of Uzbekistan. №1022 26 December 2017. Retrieved from https://www.lex.uz/docs/3481466?lact_id=3481466 